\section{O olbar brasileiro dos es- trangeiros sobre as relações de raça e cultura no Brasil}

Livio SANSONE. Negritude sem etnicidade: o local e o global nas relações raciais e na produção cultural negra do Brasil. Salvador/Rio de Janeiro, Edufba/Pallas, 2003. 335 páginas [Blacknesss without ethnicity: constructing race in Brazil. Nova York, Palgrave Macmillan, 2003. 248 páginas].

\section{Jeferson Bacelar}

A história da antropologia brasileira sempre foi marcada pela contribuição de estrangeiros, muitos deles fundadores de linhagens, como foi o caso de Claude Lévi-Strauss e Roger Bastide. Em particular, na área dos estudos sobre as relações raciais e sobre a presença dos componentes africanos na formação e no desenvolvimento da cultura brasileira, ganha destaque a participação dos pesquisadores estrangeiros. Com visitas esporádicas ou constantes, escolhendo o Brasil para morar alguns anos ou vivendo até o fim dos seus dias, muitos dos pesquisadores estrangeiros foram responsáveis pela renovação teórica, pelo aporte de novas metodologias e por pioneiros conhecimentos etnográficos para uma antropologia do Brasil. Muitos que aqui estiveram ou que ainda permanecem são inteiramente comprometidos com o seu imaginário de origem ou com as vigências acadêmicas de pólos hegemônicos; outros, sem desprezar suas origens e sua formação na Academia internacional, optaram por imergir no imaginário nacional, tornando-se quase brasileiros no pensar, ver e sentir a nossa realidade social e cultural.

Livio Sansone enquadra-se perfeitamente nessa última categoria e possui uma trajetória existencial e acadêmica singular. Italiano de origem, desenvolveu inicialmente suas pesquisas na Holanda com populações de origem africana e posteriormente chegou à cidade de Salvador. Aqui, realizou extensa pesquisa sobre relações raciais em duas áreas periféricas da Bahia e após alguns anos, já casado com uma baiana, mudou-se para o Rio de Janeiro, onde prosseguiu suas investigações sobre as populações negras e suas manifestações culturais. No início do novo século retornou a Salvador e integrou-se ao Departamento de Antropologia da Universidade Federal da Bahia, já agora SE encaminhando para a compreensão dos meandros do Recôncavo. Perfazem, portanto, mais de dez anos de investigação da cultura brasileira, expostos em publicações, palestras, seminários, conferências no território nacional, nos Estados Unidos, na Europa e na África. Recentemente, honrou-nos com a reunião de suas publicações em um único e extenso livro, simultaneamente lançado em português e inglês: Negritude sem etnicidade: o local e o global nas relações raciais e na produção cultural negra do Brasil [Blacknesss without ethnicity: constructing race in Brazil].

Escrito de forma fácil e acessível, resultado de suas pesquisas e observações efetuadas em Amsterdam, Rio de Janeiro e Bahia, no caso, especialmente em Salvador, o livro é uma reflexão ampla e consistente sobre a produção acadêmica e a realidade vivenciada pelos negros brasileiros. $\mathrm{O}$ fundamental, e por isso o seu caráter polêmico, é que suas interpretações se afastam dos postulados vigentes em grande parte das posições estabelecidas em torno da raça e da cultura dos negros na Academia brasileira.

Seu pressuposto básico é a visão do negro como um componente da sociedade brasileira, não podendo ser entendido de forma autônoma, isola$\mathrm{da}$, independente das dinâmicas externa e interna que marcam a nossa configuração cultural. A história do Brasil foi construída com base nos fluxos globalizantes e, portanto, o negro não passou ao largo desses processos mais gerais que envolveram a sociedade e a cultura brasileiras. Nesses tempos de modernidade avançada, de exacerbação da comunicação e da informação, mais do que nunca os ecos internacionais participam e influenciam a nossa realidade. Porém, nosso caráter periférico será marcado pela especificidade do processo civilizatório brasileiro: a colonização portuguesa, o catolicismo brasileiro, a diversidade étnica e social dos africanos e seus descendentes, a miscigenação constante e aceita, a ideologia da assimilação, o 
continuum de cor e sua ambigüidade, a cordialidade e o racismo estrutural. Enfim, para entender o negro e sua cultura na sociedade brasileira é indispensável relacioná-lo com a estrutura social e sua dinâmica, envolvidas pelos processos de globalização e modernidade. No entanto, é necessário também que haja uma compreensão do negro e de sua inserção social no âmbito mesmo de nossa cultura, isto é, a partir de nossas visões ou concepções específicas, sem sucumbir diante do poder e das hegemonias acadêmicas vigentes nos países centrais.

A história das relações raciais no Brasil, desde o século XIX, foi marcada pela diferença em relação ao que se deu nos Estados Unidos. Nas últimas décadas, entretanto, passamos da idéia estabelecida de que vivemos em um "paraíso racial" para a visão de um "inferno racial". Em outras palavras, ganhou força na Academia e no interior da militância negra brasileiras a perspectiva analítica de que a solução polarizada norte-americana negros versus brancos - deveria ser, também para o Brasil, o modelo a ser perseguido, tendo em vista o estágio econômico, político e social alcançado pelos afro-americanos. Livio Sansone mostra que esse modelo não pode ser transplantado para o Brasil, devido a nossas especificidades, e propõe que se amplie a base comparativa para além do mundo anglo-saxônico. Embora concorde com a perspectiva do autor, questiono, em contrapartida, um outro aspecto do prisma comparativo: os pesquisadores norte-americanos no Brasil têm refletido sobre o atual estágio das pesquisas realizadas nos Estados Unidos sobre as relações raciais? Aquela polarização referida manteve-se estática, sem transformações substanciais nas últimas décadas nos Estados Unidos? Ou melhor, não teriam surgido novos sujeitos coletivos advindos da mestiçagem, que podem ter provocado fendas na estabelecida polarização? Será que também nos Estados Unidos o critério da aparência não começa a ser considerado importante para entender as relações raciais? Em suma, a realidade norte-americana não estaria hoje mais próxima da brasileira? Talvez as investigações de caráter comparativo não devessem ser estabelecidas a partir de um "modelo" - construído por esses pesquisadores -, mas deveriam implicar um conhecimento sistema- tizado das duas realidades, como o faz Sansone em relação a Amsterdam e Salvador. Portanto, embora acredite na necessidade da ampliação de perspectivas, proposta pelo autor, ainda vislumbro nos Estados Unidos um excelente "porto para a navegação e as descobertas". Considero que, do ponto de vista histórico, a assunção do modelo de polarização pela militância negra no Brasil foi fundamental, uma vez que, diante do mito da democracia racial e da larga mestiçagem, criou a possibilidade de o grupo aumentar sua visibilidade em seu próprio interior e em esfera nacional. Foi por meio de choque com a concepção cristalizada de "paraíso racial" que uma minoria atuante conseguiu o reconhecimento do negro na sociedade .

Segundo Livio Sansone, as identidades nas sociedades modernas, antes que unificadas, substancializadas, são fluidas, múltiplas, consoante o capital social e cultural acumulado pelos indivíduos. Em outras palavras, ninguém é somente negro na vida social; existem várias formas de assunção da identidade racial. $\mathrm{O}$ autor mostra que muitos fatores influenciam a emergência da negritude, desconstruindo a possibilidade de uma naturalidade intrínseca. Inicia por ressaltar que um número relativamente grande de pessoas de pele mais escura não se traduz numa organização societária, política e econômica específica, seja pela mestiçagem, seja pela participação desigual nos recursos da sociedade. Considera, contudo, que a demografia seja importante para a definição da condição de uma minoria racial, o que fortaleceria sua identidade e organização. Isso, segundo o autor, não ocorre no Brasil, pois o negro se sente um componente do povo brasileiro.

A questão da relação entre raça e classe assume, para Sansone, um papel primordial para a compreensão da identidade negra no Brasil. A classe, muito mais que a raça, sempre foi um demarcador mais preciso das posições do indivíduo na sociedade, daí ela se apresentar como um vetor constante na mobilização política coletiva dos negros. Ao contrário das ambigüidades acerca da classificação de cor na sociedade brasileira, no geral entendem-se as distinções de classe - todo mundo sabe quem é "barão" ou "peão" . E isso, conforme assevera Norbert Elias, indica que quan- 
to maior a desigualdade de recursos e poder na sociedade, mais prepondera para o dominado a luta pela sobrevivência, antes da busca por maiores aspirações na sociedade. Daí Sansone afirmar que a pobreza e a miséria são grandes inimigas da formação da consciência racial. Assim, a emergência da nova consciência racial no Brasil e, em particular, na Bahia foi resultante de um novo padrão de desenvolvimento e de mobilidade social, que melhoraram as condições de vida dos contingentes negros. O autor atenta para a emergência de uma classe média negra - não seriam negros na classe média? -, formada por empresários e profissionais liberais, com um estilo de vida similar à classe média branca, mas que afirma de modo enfático sua negritude. Trata-se de um contingente significativo, o qual subverte as interpretações que associam a negritude à pobreza. Sansone demonstra também que a identidade racial está associada à faixa etária - "pai preto, filho negro" -, assim como ela é manipulada conforme o espaço ocupado pelo individuo, o que cria "áreas duras e áreas moles", onde ele poderá se sentir mais ou menos à vontade na afirmação de sua negritude. Além disso, o autor ressalta, sobretudo, que a identificação racial não implica necessariamente uma militância política, muito menos um conflito com os brancos ou com o mundo dos brancos. São bastante pertinentes suas observações sobre a mestiçagem, na medida em que, ideologicamente, em vários momentos históricos, ela tem sido a responsável tanto por gerar "um mal-estar generalizado" como por significar a "solução brasileira" para o problema do negro na sociedade. Porém, assevera o autor, nenhum estudo rigoroso foi desenvolvido sobre os mestiços brasileiros. Em um momento, por exemplo, eles deveriam tornar-se brancos, em outro, negros, mas ninguém perguntou o que eles são, o que pensam ou o que querem. Ou seria todo mestiço substancialmente um "alienado"?

Quando aborda a cultura negra no Brasil, o autor investe contra a visão multiculturalista, que pressupõe uma cultura específica e integrada para cada grupo, o que não reflete a fragmentação social, a assimilação fragmentada e a importância da classe. Demonstra, além disso, a historicidade e as transformações da cultura negra baiana tradicional, em se tratando dos "usos e abusos da africanidade" no Brasil, assim como as formas renovadas de produção, consumo e mercantilização cultural. Analisa também a condição mista e sincrética dessa cultura, contrapondo-a tanto à perspectiva do imobilismo e da autenticidade (pureza), como à associação entre raça e cultura, uma vez que apenas uma minoria dos negros participa dela. Na minha concepção, nas últimas décadas do século $\mathrm{XX}$, O grupo racial vem tentando transmutar-se em grupo étnico, buscando uma vertente cultural tradicional para afirmar a sua especificidade, ou seja, a pretensão de uma identidade racial afro-descendente. Porém, a racialização não tem sido uma perspectiva de maior vigência entre os grupos culturais. A realidade mostra-se mais complexa, conforme afirma Sansone, com a presença da "nova cultura negra", reflexiva da globalização, da força dos meios de comunicação e da formação de redes internacionais integradas à modernidade, com fortes ligações com a cultura juvenil e suas dimensões estéticas. Enfim, a "nova cultura negra" - e mesmo a tradicional - cada vez mais se identifica com a modernidade avançada, muito distante dos "valores prémodernos" e de uma certa concepção nostálgica que tem o passado como um símbolo de referência. Quanto à "ponte" entre raça e etnia - a grande confusão conceptual do autor -, o que pode ser assinalado é que a identidade cultural (negra) não estabelece uma relação causal com as formulações coletivas da identidade racial da militância política negra. Em outras palavras, o indivíduo pode ser rastafari, membro de um grupo cultural negro ou do candomblé, mas isso não quer dizer que ele problematize a questão racial ou se envolva necessariamente com os "movimentos negros".

Livio Sansone assume, então, que é possível existir uma postura anti-racista sem a assunção da identidade (polarizada) racial e étnica. Como esses conceitos são apresentados de forma bastante ambígua na obra do autor, o leitor pode se perguntar se Sansone escreve para a militância ou para os acadêmicos. Se seu postulado "universalista" dirige-se à militância, seria possível mudar a realidade política racial brasileira sem que houvesse simplificação ou radicalização do movimento? A militância desconhece os problemas advindos da identidade polarizada? 
É evidente que se pode ser anti-racista sem aceitar ou se integrar na polarização racial, mas entre essa perspectiva e a posição de que a "definição estreita de negritude [...] pode constituir um obstáculo à criação de um movimento amplo pelos direitos civis que atraia pessoas de classes e credos diferentes" (p. 294) há uma longa distância. Primeiro, tenho dúvidas quanto à possibilidade real de existir um "movimento amplo pelos direitos civis" com definições estreitas ou amplas acerca da negritude; segundo, a polarização, com todos os seus efeitos, desenvolvida por uma minoria atuante, antes que um obstáculo tem sido a responsável pela mudança desencadeada na realidade política racial e social brasileira.

Do ponto de vista acadêmico, concordo com a perspectiva de Sansone a favor de "uma curiosidade etnográfica" capaz, sem apriorismos, de identificar as características específicas da nossa configuração racial e cultural. Portanto, apoio inteiramente sua proposta de um olhar brasileiro sobre o Brasil, sem vergonha de aceitar a mestiçagem e a hibridez de nossa cultura, que sempre coexistiram com uma imensa injustiça social. $\mathrm{Ne}$ gritude sem etnicidade merece ser lido seja pelo vasto conteúdo histórico, antropológico e sociológico, respaldado nas investigações do autor, seja pelas posições assumidas por ele. Com certeza, o leitor não ficará isento, pois, acima de tudo, tratase de um livro que incomoda.

Jeferson BACELAR é professor do Departamento de Antropologia da UFBA e pesquisador do Centro de Estudos Afro-Orientais. E-mail: bacelarj@ufba.br

\section{Representações sociais $e$ sociedades: a contribuição de Serge Moscovici}

Serge MOSCOVICI. Representações sociais: investigações em psicologia social. Rio de Janeiro, Vozes, 2003. 404 páginas (trad. Pedrinho A. Guareschi, a partir do original em língua inglesa Social representations: explorations in social psychology [Gerard Duveen (ed.), Nova York, Polity Press/Blackwell Publishers, 2000]).

Márcio S. B. S. de Oliveira

O romeno naturalizado francês Serge Moscovici é dono de uma obra considerável, tão importante para a psicologia (seu campo de formação e atuação) como para a história e as ciências sociais. Seus trabalhos e sua teoria das representações sociais (TRS) têm influenciado ao longo das últimas quatro décadas pesquisadores tanto na Europa como nas Américas, incluindo o Brasil. ${ }^{1}$ É curioso, assim, que entre sua vasta obra - doze livros individuais e quatorze que ele organizou ou escreveu em conjunto com outros autores -, apenas dois tenham sido traduzidos para o português, ambos com edições esgotadas. ${ }^{2}$ É com prazer, portanto, que apresento ao leitor a tradução de Social representations: explorations in social psychology, terceiro livro de Moscovici.

O leitor não encontrará neste livro uma tese formalmente defendida. Ao contrário, o que se tem são capítulos independentes. Contudo, a impressão inicial de uma "coletânea" de um só autor logo se esvai. Isto porque Moscovici, desde o final dos anos de 1950 e início da década de 1960, preocupa-se com os mesmos temas, retomados em perspectiva ao longo dos seis capítulos que compõem a obra. Trata-se de temas como o processo social de produção de conhecimento, a definição de sociedade e a discussão em torno das representações sociais. No interior das ciências sociais, sua obra pode ser inserida no campo da sociologia do conhecimento; e acredito que esta classificação, embora reducionista, não desagradaria ao autor. Reducionista porque Moscovici se 